\title{
Movements and space use of giant trevally in coral reef habitats and the importance of environmental drivers
}

\author{
Elodie JI Lédée $e^{1,2^{*}}$, Michelle R Heupel ${ }^{1,3}$, Andrew J Tobin ${ }^{1}$ and Colin A Simpfendorfer ${ }^{1}$
}

\begin{abstract}
Background: Effective conservation of large predators requires a broad understanding of their ecology. Caranx ignobilis is a large marine predator well represented in coral reef environments, yet they are poorly studied. Passive acoustic monitoring was used to track the movements of 20 C. ignobilis at offshore reefs in the central Great Barrier Reef from 2012 to 2014. Using a modelling approach, temporal changes in movement patterns of C. ignobilis were explored to determine if individuals exhibited predictable movement patterns. The effects of biological and environmental variables on monthly space use, daily presence and hourly depth use were investigated to define any response to environmental changes.

Results: Caranx ignobilis typically remained at their capture reef with $98.8 \%$ of detections recorded at these locations. Individuals were recorded in the study site for periods from 9 to 335 days (mean $=125.9$ ) with a mean residency index of 0.53 , indicating movements away from the reef or out of detection range occurred on the scale of days. Inter-reef movements from only three individuals were recorded which coincided with the summer full moon so may have been related to spawning behaviour. Environmental drivers were correlated with daily presence and hourly depth use of $C$. ignobilis but had little influence on monthly space use. There was little or no effect of fish size on space use, presence and depth use.

Conclusion: By improving the current understanding of movement patterns of this large teleost among individual coral reefs, the results of this study reveal that site attachment may be present and that environmental parameters play a role in observed movement patterns related to depth and presence. These data provide useful information for the development of management plans, particularly in relation to space-based protection.
\end{abstract}

Keywords: Acoustic monitoring, Depth use, Information theoretic approach, Mixed-effects model, Occurrence, Residency

\section{Background}

Coral reef ecosystems are biologically diverse and economically important but are under threat due to fisheries pressure and climate change [1]. Changes in environmental and human-related factors can have significant effects on coral reef ecosystems. These changes not only impact coral species but also mobile reef species such as sharks and large teleosts and their interactions with the

\footnotetext{
* Correspondence: elodie.ledee@my.jcu.edu.au

${ }^{1}$ Centre for Sustainable Tropical Fisheries and Aquaculture, College of Marine and Environmental Sciences, Building 34, James Cook University, Townsville, Queensland 4811, Australia

2AIMS@JCU, Australian Institute of Marine Science, College of Marine and Environmental Sciences, Building 17, James Cook University, Townsville, Queensland 4811, Australia

Full list of author information is available at the end of the article
}

ecosystem ([2-4], Currey LM, Heupel MR, Simpfendorfer CA, Williams AJ: Do environmental variables influence movement patterns of an exploited coral reef fish?, forthcoming). Past research has investigated the effects of environmental change on large-bodied teleost distribution [4]; however, few studies have investigated largebodied teleosts in coral reef habitats. Furthermore, understanding how environmental changes or disturbances affect highly mobile reef teleosts remains a challenge due to long distance movement and use of a wide variety of habitats [5,6]. Thus, while studies of reef fish movement have become more common [7], knowledge remains limited on the role environmental factors play in controlling movements and space use [8-10]. 
Top predators are known to play a central role in maintaining coral reef ecosystem structure and function $[2,9,11]$. For example, predation by large-bodied reef teleosts controls prey populations and community structure and maintains dominance hierarchies [2,9,12]. Declines in top predator populations can result in changes in coral reef communities such as higher abundance of prey altering species interactions and habitat use that may result in trophic cascades $[4,9,11]$. Top predators are often targeted by fisheries $[4,13]$, and past research has shown declines in predator abundance and shifts in their distribution on many coral reefs due to overfishing [13-15]. Furthermore, top predator movement patterns are also influenced by changes in environmental factors. How species respond to environmental change is a function of their biology and physiology [16,17]. Recent research has shown water temperature to be an important factor in the distribution of the reef predator Lethrinus miniatus (Currey LM, Heupel MR, Simpfendorfer CA, Williams AJ: Do environmental variables influence movement patterns of an exploited coral reef fish?, forthcoming) and that seasons influence the movement patterns of sharks and pelagic teleosts [13,18-20]. However, our understanding of how changes in environmental conditions affect coral reef predator movement is limited ([3], Currey LM, Heupel MR, Simpfendorfer CA, Williams AJ: Do environmental variables influence movement patterns of an exploited coral reef fish?, forthcoming). Therefore, understanding how large-bodied reef teleosts move and respond to changes within their environment is critical for understanding how best to manage these species, including the benefits that they derive from marine protected areas [6,12].

Caranx ignobilis, the giant trevally, is a common, highly mobile predator in tropical and subtropical waters that has been poorly studied given their abundance [21,22]. Information on their reproduction, movement patterns and habitat use is limited. Caranx ignobilis are targeted by commercial and recreational fisheries throughout much of their Indo-Pacific range, including in Hawaii [21,22], and the Great Barrier Reef (GBR), Australia. Given their abundance and importance, information on the ecology of $C$. ignobilis will help improve understanding of their role in coral reef ecosystems and improve management where it is required [3,13]. Accordingly, the main aims of the research were to investigate movement patterns of this large teleost within and among individual coral reefs, examine temporal changes in presence/absence, space use and depth use and determine the role of biological and environmental factors in affecting these attributes.

\section{Results}

From 2012 to 2014, 20 C. ignobilis were released with acoustic transmitters within the offshore reefs array in the central GBR region. Four C. ignobilis were not detected, and a further six were infrequently detected $(<15$ detections) and were excluded from further analysis. Sizes of the ten remaining fish ranged from 48.5 - to $104.0-\mathrm{cm}$ fork length (mean $\pm \mathrm{SD}=79.9 \pm 16.1$ ); and length did not differ between tagging reef $\left(F_{3,5}=2.63, P=0.16\right)$. Caranx ignobilis reach maturity between 55 - and $65-\mathrm{cm}$ fork length [22], so one individual was likely to be subadult at time of capture and the remainder mature. Individuals were mostly detected at the reef they were caught on (98.8\% of detections; Table 1). Only three individuals were detected at non-tagging reefs, all during 3 weeks in October 2013 when they were recorded at reefs located from 8 to $38 \mathrm{~km}$ away from their tagging reef.

Individuals were present in the study site on average $( \pm$ SD) $126 \pm 128$ days (Figure 1 , Table 1 ). The mean maximum consecutive days detected $( \pm \mathrm{SD})$ during the study period was $53 \pm 76$. The number of days detected and maximum consecutive days did not vary between reefs $\left(F_{3,6}=2.51, P=0.16\right.$ and $F_{3,6}=1.93 P=0.23$, respectively). Furthermore, $C$. ignobilis showed significant diel variation in detections (paired $t$-test: $t_{11}=5.16, P<0.001$ ), with less detections recorded per hour during daytime (mean $\pm \mathrm{SE}=$ approximately $12.4 \pm 3.4$ ) than nighttime (mean $\pm \mathrm{SE}=$ approximately $43.8 \pm 5.1$ ). After correction for diel detection patterns based on sentinel tags (Additional file 1 showing mean number of detections per hour), results did not change significantly (mean $\pm \mathrm{SE}=$ approximately $14.92 \pm 2.70$ during the day and approximately $37.03 \pm 3.96$ at night) with significant diel variation apparent (paired $t$-test: $\left.t_{11}=5.90, P<0.001\right)$. Only individuals that were detected from April 2013 to April 2014 $(n=8)$ were included in generalized linear mixed-effects modelling.

\section{Presence/absence}

Mean C. ignobilis residency index was $0.53( \pm 0.11 \mathrm{SE})$, and there was no difference in residency index between reefs $\left(F_{3,6}=1.50, P=0.31\right.$; Table 1$)$. Multi-model inference using an information theoretic approach (that is, Akaike information criterion $\left(\mathrm{AIC}_{c}\right)$ ranking) was used to explain fish size and environmental effects on C. ignobilis daily presence/absence. Seven binary nested models best fit the data $\left(\Delta \mathrm{AIC}_{c}<2\right)$, and all models were significantly better than the null model $(P<0.001$; Additional file 2 a showing top nested mixed-effects models examining fish size and environmental variables effects on $C$. ignobilis presence). All seven nested models included water temperature, wind speed and light intensity as fixed variables.

The mixed-effects model showed that daily presence/ absence was influenced by season (Table 2) with C. ignoblis more likely to be detected during winter than summer months (Figure 2a). Water temperature, wind speed, and light intensity were found to have a significant effect on the daily presence/absence of $C$. ignobilis (Table 3) with 
Table 1 Tagging data for ten Caranx ignobilis monitored in central Great Barrier Reef

\begin{tabular}{|c|c|c|c|c|c|c|c|c|c|}
\hline ID & Capture location & Tagging date & $\mathrm{FL}(\mathrm{cm})$ & $\begin{array}{l}\text { Number of } \\
\text { detections }\end{array}$ & $\begin{array}{l}\text { Detection at } \\
\text { tagging reef (\%) }\end{array}$ & $\begin{array}{l}\text { Total days } \\
\text { present }\end{array}$ & $\begin{array}{l}\text { Days at } \\
\text { liberty }\end{array}$ & $\begin{array}{l}\text { Consecutive } \\
\text { days present }\end{array}$ & $\begin{array}{l}\text { Residency } \\
\text { index }\end{array}$ \\
\hline 7009 & Wheeler Reef & 24 April 2013 & 84.0 & 6,935 & 100.0 & 335 & 356 & 168 & 0.94 \\
\hline 7011 & Wheeler Reef & 24 April 2013 & 74.5 & 1,294 & 94.4 & 181 & 347 & 36 & 0.52 \\
\hline 7012 & Helix Reef & 25 April 2013 & 84.0 & 199 & 93.9 & 32 & 331 & 7 & 0.10 \\
\hline 7015 & Helix Reef & 20 February 2013 & 90.5 & 995 & 100.0 & 180 & 371 & 29 & 0.49 \\
\hline 7016 & Helix Reef & 20 February 2013 & 65.0 & 6,338 & 99.9 & 332 & 358 & 218 & 0.93 \\
\hline 7013 & Lodestone Reef & 19 February 14 & 104.0 & 168 & 100.0 & 28 & 57 & 8 & 0.49 \\
\hline 7014 & Lodestone Reef & 19 November 2013 & 96.5 & 1,416 & 100.0 & 131 & 147 & 54 & 0.89 \\
\hline 7018 & Lodestone Reef & 18 February 2013 & 48.5 & 196 & 100.0 & 9 & 12 & 5 & 0.75 \\
\hline 7022 & Keeper Reef & 11 February 13 & 71.0 & 84 & 100.0 & 14 & 200 & 2 & 0.07 \\
\hline 7028 & Keeper Reef & 30 April 2012 & 81.0 & 97 & 100.0 & 17 & 53 & 7 & 0.32 \\
\hline
\end{tabular}

greater likelihood of detection with decreases in water temperature, light intensity and wind speed (Figure 3a,b,c).

\section{Space use}

Core use (50\% vertical kernel utilisation distribution (vKUD)) and extent (95\% vKUD) areas varied between individuals and months. Monthly core use areas ranged from approximately $0.001 \mathrm{~km}^{2}$ to approximately $0.016 \mathrm{~km}^{2}$ (mean \pm SE $=$ approximately $0.006 \pm 0.0004$ ) and extent from approximately $0.004 \mathrm{~km}^{2}$ to approximately $0.062 \mathrm{~km}^{2}$ (mean $\pm \mathrm{SE}=$ approximately $0.032 \pm 0.002$ ) (Figures 4 and 5). However, there was no significant difference between months (core use $\chi_{2}^{2}=0.44, P=0.51$; extent $\chi_{2}^{2}=$ $0.69, P=0.40)$. Overall, smallest individuals had the largest core use and extent areas within the study region. At Helix and Lodestone Reefs, smaller individuals used more space (48\% and 19\% more, respectively) compared to larger fish. However, at Wheeler Reef, smaller individuals used less space than larger fish (55\% less).

Monthly space use overlap did not vary between individuals (core use $F_{1,6}=0.63, P=0.46$; extent $F_{1,6}=1.18$, $P=0.32$ ) (Figure 6a). Mean monthly space use overlap ranged from $0 \%$ to $56 \%$ (mean $\pm \mathrm{SE}=21 \% \pm 6 \%$ ) for core use and from $0 \%$ to $71 \%$ (mean $\pm \mathrm{SE}=31 \% \pm 7 \%$ ) for extent. Overlap between co-occurring individuals ranged

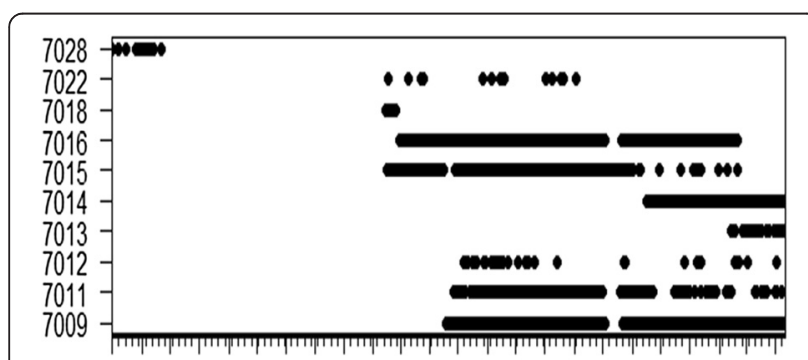

May 2012 Sep 2012 Jan 2013 May 2013 Sep $2013 \operatorname{Jan} 2014$

Figure 1 Daily detection history of ten tagged Caranx ignobilis from May 2012 to April 2014. from $0 \%$ to $52 \%$ (mean $\pm \mathrm{SE}=15 \% \pm 3 \%$ ) for core use and from $0 \%$ to $81 \%$ (mean $\pm \mathrm{SE}=28 \% \pm 7 \%$ ) for extent (Figure 6b) and varied greatly between reefs (core use $F_{3,3}=10.72, P<0.05$; extent $\left.F_{3,3}=15.67, P<0.03\right)$. Individuals at Wheeler Reef had higher overlap ( $>50 \%$ for core use) compared to the other two reefs $(<20 \%$ for core use).

Multi-model inference using an information theoretic approach identified five nested models for core use (Additional file $2 \mathrm{~b}$ showing top nested mixed-effects models examining fish size and environmental variables effects on $C$. ignobilis core use) and four for extent (Additional file 2c showing top nested mixed-effects models examining fish size and environmental variables effects on $C$. ignobilis extent) that met the best fit criteria $\left(\Delta \mathrm{AIC}_{c}<2\right)$. Null models were included in the best fitted nested models for core use and extent. None of the core use nested models were significantly better than the null model $\left(\chi^{2}, P>0.19\right.$; Additional file $\left.2 \mathrm{~b}\right)$, whereas two of the extent nested models were significantly better than the null model $\left(\chi^{2}, P<0.05\right.$; Additional file 2c). Finally, mixed-effects model showed no seasonal effect (Table 1), and model averaging showed no fish size or environmental effects on monthly space use (Additional file $3 \mathrm{a}, \mathrm{b}$ showing fish size and environmental variables effects on $C$. ignobilis space use from model averaging

Table 2 Seasonal effects on Caranx ignobilis presence, space use and depth in central Great Barrier Reef

\begin{tabular}{llll}
\hline Model & $\boldsymbol{X}^{\mathbf{2}}$ & $\boldsymbol{d f}$ & $\boldsymbol{P}$ value \\
\hline $\mathrm{PA} \sim$ Season & 73.88 & 3 & $<0.0001^{*}$ \\
$\mathrm{CU} \sim$ Season & 3.40 & 3 & 0.33 \\
EX $\sim$ Season & 6.28 & 3 & 0.10 \\
$\mathrm{MD} \sim$ Season & 340.30 & 3 & $<0.0001^{*}$
\end{tabular}

PA: daily presence, CU: monthly core use (50\% vertical kernel utilization distribution vKUD), EX: monthly extent (95\% vKUD) and MD: hourly mean depth. Asterisks indicate significant effect $(P<0.05)$ via Wald $Z$ test using chisquared test against null model. 


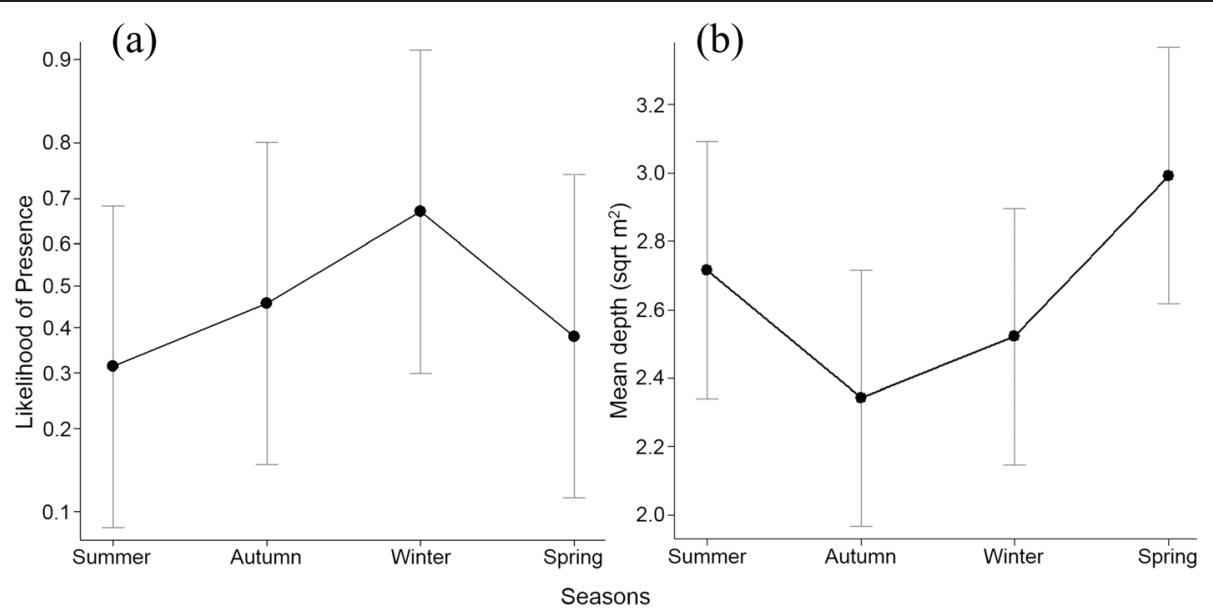

Figure 2 Effect of season on the daily presence and hourly mean depth of Caranx ignobilis. Daily presence (a) and hourly mean depth (b) of Caranx ignobilis in the central Great Barrier Reef were examined from April 2013 to April 2014. Dots indicate mean presence (a), and mean depth (b) with error bars representing $95 \%$ confidence intervals.

analysis) indicating that none of these factors were important drivers of space use.

\section{Depth use}

Hourly mean depth ranged from 0.0 to $27.0 \mathrm{~m}$ (mean \pm $\mathrm{SE}=7.0 \pm 0.08)$ between April 2013 and April 2014 and did not vary between individuals or reefs $\left(F_{6,1}=0.65\right.$, $P=0.45$ and $F_{3,4}=0.62, P=0.64$, respectively). Four generalized linear mixed-effects nested models had a $\Delta \mathrm{AIC}_{c}<2$ and were all significantly better than the null model $(P<0.0001$; Additional file $2 \mathrm{~d}$ showing top nested mixed-effects models examining fish size and environmental variables effects on C. ignobilis mean depth). All nested models included light intensity, water temperature, tide height, and wind speed as fixed variables (Additional file $2 \mathrm{~d}$ ).

Seasonal effects on hourly mean depth use were shown by the mixed-effects model (Table 2). During spring, individuals were found deeper in the water column whereas during autumn, they were found closer to the surface (Figures $2 \mathrm{~b}$ and 5 ). Results from model averaging showed that C. ignobilis hourly mean depth was influenced by light intensity, tide height and wind speed though not fish size (Table 4). As light intensity and water movement increased and wind speed decreased, C. ignobilis were found deeper in the water column (Figure 3d,e,f). Although water temperature was present in all best fitted nested models and had $81 \%$ of relative importance with shrinkage, the effect was not significant with less than $10 \%$ of mean depth estimates showing a relationship with increases in water temperature (Table 4).

\section{Discussion}

This research demonstrated that adult and subadult $C$. ignobilis had high levels of fidelity to individual reefs, and their detection at these reefs was driven by a number of environmental factors. The high level of fidelity to their tagging reef is in contrast to the strong swimming ability of this species $[23,24]$ and reports of relatively large home ranges either directly [7] or from allometric relationships between body size and home range size [22,25]. While they have good swimming ability and are designed for

Table 3 Environmental and fish size effects on Caranx ignobilis presence from model averaging analysis

\begin{tabular}{|c|c|c|c|c|}
\hline & Estimate Std. \pm SE & $Z$ value & $P$ value & Relative importance \\
\hline (Intercept) & $0.000 \pm 0.000$ & NA & NA & - \\
\hline Light intensity & $-0.554 \pm 0.155$ & 3.583 & $<0.001^{*}$ & 1.00 \\
\hline Rainfall & $-0.151 \pm 0.153$ & 0.990 & 0.322 & 0.65 \\
\hline Water temperature & $-1.538 \pm 0.195$ & 7.895 & $<0.0001^{*}$ & 1.00 \\
\hline Tide height & $0.159 \pm 0.218$ & 0.730 & 0.465 & 0.51 \\
\hline Wind speed & $-0.595 \pm 0.137$ & 4.345 & $<0.0001^{*}$ & 1.00 \\
\hline Moon illumination & $-0.050 \pm 0.101$ & 0.489 & 0.625 & 0.38 \\
\hline Fork length & $0.121 \pm 0.749$ & 0.162 & 0.872 & 0.28 \\
\hline
\end{tabular}

Environmental parameters were standardised for comparison. Asterisks indicate significant effect $(P<0.05)$ on daily presence of Caranx ignobilis monitored in the central Great Barrier Reef. 

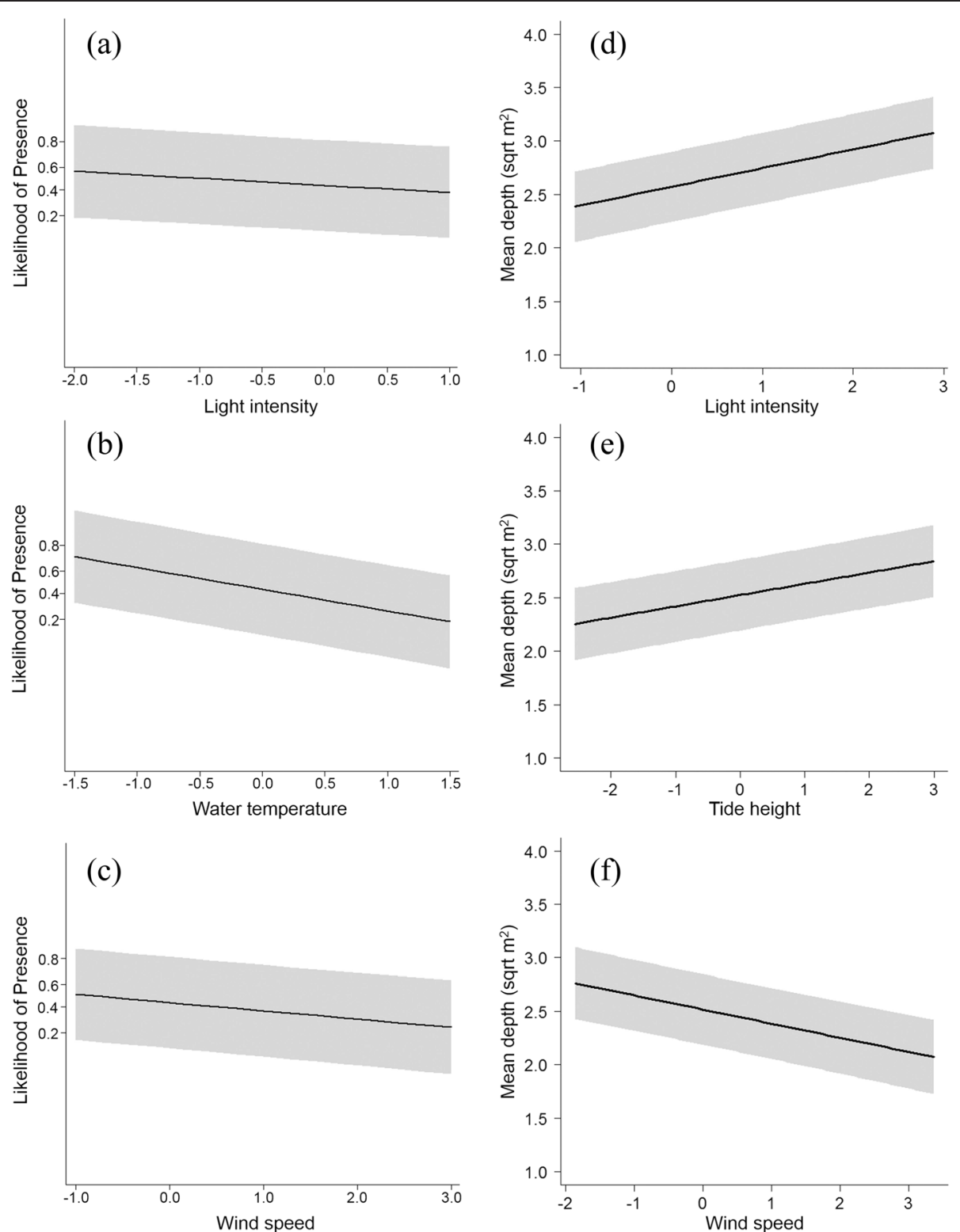

Figure 3 Environmental effects on the daily presence and hourly mean depth of Caranx ignobilis. Results of mixed-effects models indicating the effects of light intensity $(\mathbf{a}, \mathbf{d})$, water temperature $\mathbf{( b )}$, tidal height $(\mathbf{e})$ and wind speed $(\mathbf{c}, \mathbf{f})$ on the daily presence $(a, b, c)$ and hourly mean depth (d, e, f) of Caranx ignobilis in the central Great Barrier Reef from April 2013 to April 2014. Lines represent mean presence (a, b, c), and mean depth (d, e, f) with grey shading indicating $95 \%$ confidence intervals.

high speed swimming, the data suggest that $C$. ignobilis are not 'highly mobile' because no regular inter-reef movements were observed. However, it is possible that individuals made inter-reef movements during periods of non-detection. Ten individuals were either infrequently or never detected and may have undertaken movement to other reefs. For example, among these ten individuals, four were captured and released at John Brewer Reef which has a large area with a complex reef structure, and only four receivers were deployed on the outer-edge of the reef. Consequently, those fish may have been present and maintained home ranges outside the detection range of receivers; either in the lagoon or inter-reef areas or could have moved to non-monitored reefs. Therefore, limitation in the spatial coverage of the acoustic array at some reefs may have resulted in the activity space of $C$. ignobilis being underestimated.

The main results of this work were consistent with those of studies of C. ignobilis in other locations [26] and [27] as well as for other carangid species. High residence and limited movement to other reefs or regions may be common in these species. Past studies have also reported a high 

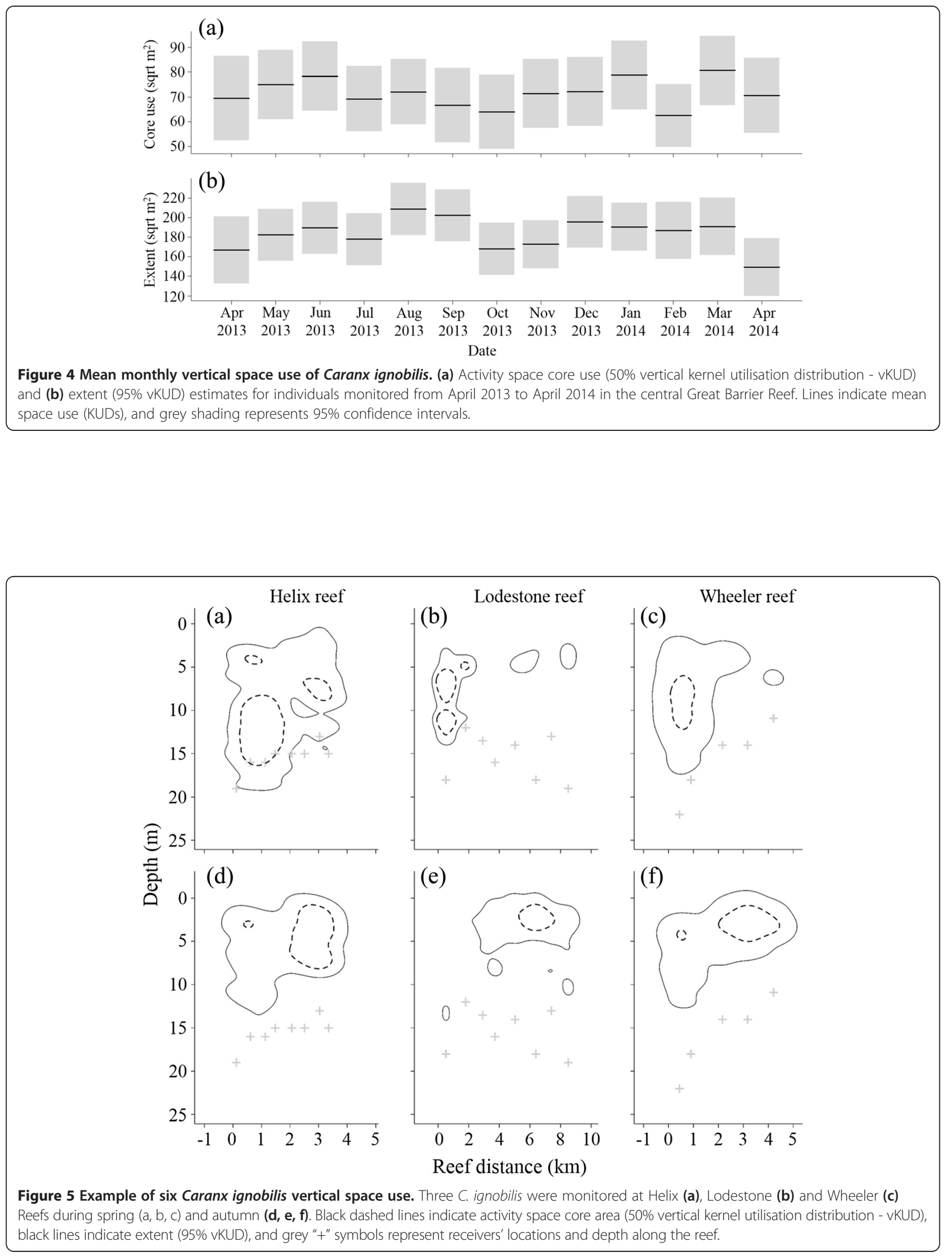


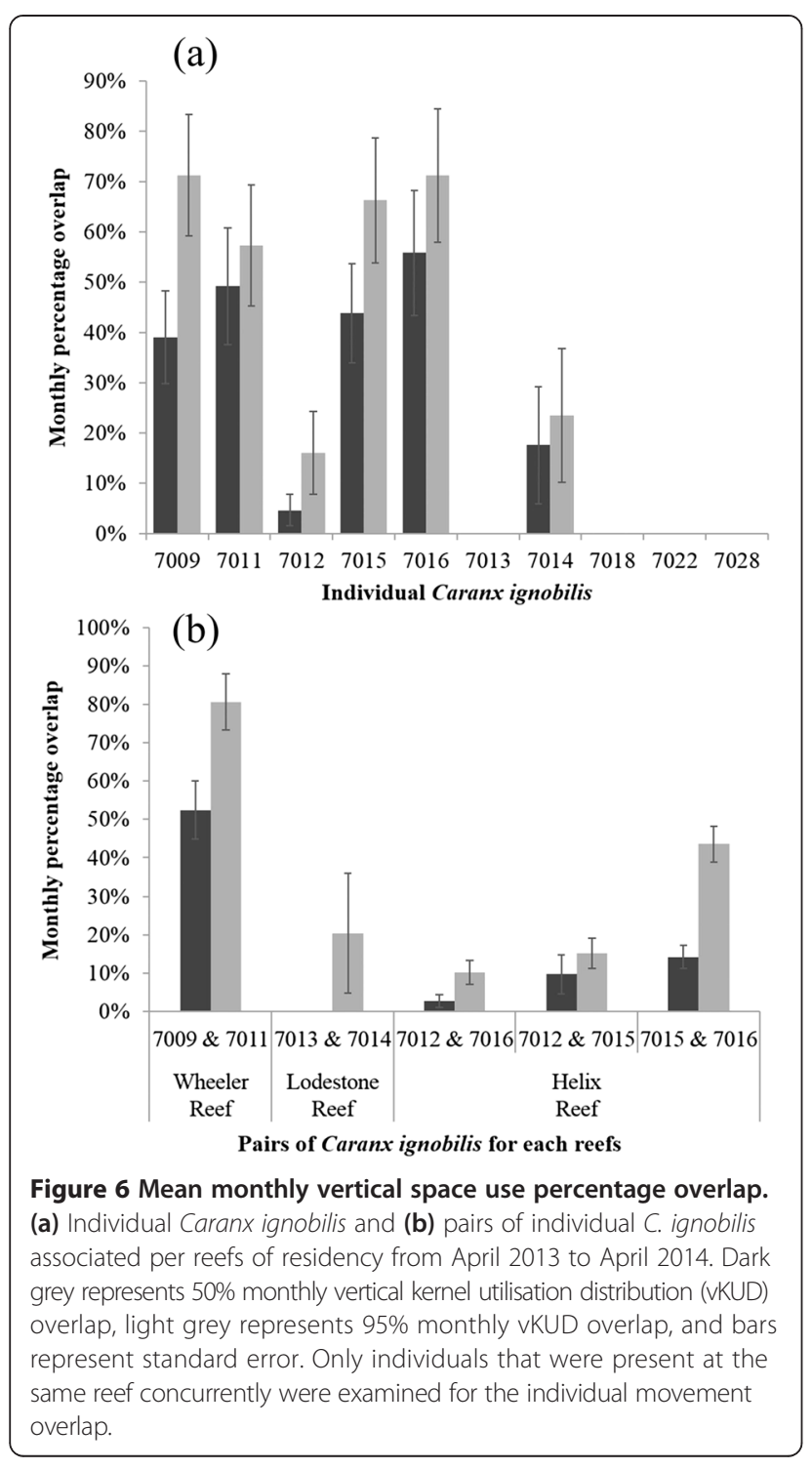

probability of presence and residency of highly mobile species at their tagging reef or location including C. ignobilis at remote Hawaiian atolls [27], Seriola rivoliana in offshore shallow seamount in the Azores [28], Thunnus albacares and Thunnus obesus at fish aggregating devices surrounding Oahu island in Hawaii [29] and Carcharhinus amblyrhynchos and Carcharhinus albimarginatus in the GBR region ([20], Espinoza M, Lédée EJI, Simpfendorfer CA, Tobin AJ, Heupel MR: Contrasting movements and connectivity of reef-associated sharks using acoustic telemetry: implications for management, forthcoming). However, long-term residency patterns were variable, and there was no evidence of differences between reefs. This suggests that $C$. ignobilis may remain present for extended periods despite differences in reef size or location.

Caranx ignobilis were detected more at nighttime, specifically the middle of the night, than during the day. However, these findings were different from Meyer et al. [27], where a significant diel variation was apparent with more detections recorded during daytime. Differences in habitat characteristics (for example, presence of a lagoon) could explain these results if individuals moved into regions where receivers were not deployed. Receivers used by Meyer et al. [27] may also have been deployed in areas that were preferentially used by C. ignobilis for daytime activities. Additionally, C. ignobilis in Wetherbee et al. [22] were found to be more active at nighttime and crepuscular periods suggesting that behaviour may be related to patrolling areas at night or shifting between locations during different periods of the day. Sudekum et al. [21] found that $C$. ignobilis predominantly ate nocturnally active prey, further suggesting individuals were foraging at night. The observed differences in behaviour between these studies could be due to the different approaches used to study the movement pattern of C. ignobilis, passive tracking in the present study and in Meyer et al. [27] versus active tracking [22]. Differences in size classes studied, adult in the present study and in Meyer et al. [27] versus juveniles [22] may also explain differences in movement patterns. These variables have important implications for understanding animal movement patterns

Table 4 Environmental and fish size effects on Caranx ignobilis mean depth from model averaging analysis

\begin{tabular}{lllll}
\hline & Estimate Std. \pm SE & $\boldsymbol{Z}$ value & $\boldsymbol{P}$ value & Relative importance \\
\hline (Intercept) & $0.000 \pm 0.000$ & NA & NA & - \\
Light intensity & $0.267 \pm 0.020$ & 13.566 & $<0.0001^{*}$ & 1.00 \\
Water temperature & $0.069 \pm 0.051$ & 1.362 & 0.173 & 0.81 \\
Tide height & $0.163 \pm 0.019$ & 8.378 & $<0.0001^{*}$ & 1.00 \\
Wind speed & $-0.192 \pm 0.026$ & 7.485 & $<0.0001^{*}$ & 1.00 \\
Barometric pressure & $0.017 \pm 0.035$ & 0.475 & 0.635 & 0.41 \\
Fork length & $0.074 \pm 0.190$ & 0.391 & 0.695 & 0.38
\end{tabular}

Environmental parameters were standardised for comparison. Asterisks indicate significant effect $(P<0.05)$ on hourly mean depth of Caranx ignobilis in the central Great Barrier Reef. 
and must be considered in comparisons and explanation of behaviours. Different approaches will provide different kinds of spatial and temporal data. Given the potential mobility of this species, multiple approaches are likely to provide the most comprehensive understanding of movement. These studies should include multiple size classes if possible.

Although C. ignobilis showed no evidence of regular inter-reef movement, they were capable of undertaking long-range movement as observed in three individuals. Interestingly, the inter-reef movements observed in this study coincided with the full moon in October. These movements were for short periods and were all undertaken by individuals that were considered adult at the time of the excursions. Caranx ignobilis is known to aggregate for spawning during summer full moon periods [27] which may explain the observed movements. Lunar timed excursions were also reported by Meyer et al. [27] and considered to be related to spawning activity. Thus, C. ignobilis inter-reef movements in the GBR may have been related to reproduction, but more research is needed to confirm this finding.

Caranx ignobilis had relatively small core use and extent activity spaces for a potentially highly mobile predator [13,22]; however, individuals occupied the entire water column [21] indicating broad vertical movements. Results were similar to past research on juvenile C. ignobilis [22] but also other carangid species such as Caranx crysos [30] and Pseudocaranx dentex [31]. Other coral reef predators such as lethrinids (for example, L. miniatus ([32], Currey LM, Heupel MR, Simpfendorfer CA, Williams AJ: Do environmental variables influence movement patterns of an exploited coral reef fish?, forthcoming) and serranids (for example, Plectropomus leopardus [33,34]) also use small activity spaces relative to reef size. This consistent pattern among piscivorous predators may be a reflection of the high productivity of reef environments [35] which allows the use of small areas while still accessing adequate prey. The similarity of area of space used between adult and juvenile C. ignobilis was interesting even though different size classes used different habitats with juveniles predominantly found in inshore bays before undertaking an ontogenetic migration to offshore reef areas when they reach maturity [22]. However, juvenile C. ignobilis in Hawaii were less resident compared to adults in the central GBR. Further research on C. ignobilis ontogenetic movement patterns in the central GBR would be needed to confirm differences in behaviour by size class in this region.

Consistent with movement patterns of other reef predators, food availability may have driven C. ignobilis movement patterns within individual reefs. Interestingly, individual core use moderately overlapped between months, indicating C. ignobilis did not have high fidelity to specific parts of the reefs but rather used various core areas that moved around individual reefs. This type of movement pattern is consistent with that of a fast swimming pursuit predator. Activity space data contrasts the activity patterns of sit-and-wait ambush predators such as leopard coralgrouper which have consistently small activity spaces in the same area $[33,34]$. Caranx ignobilis movement patterns were similar to those reported for bonnethead sharks, Sphyrna tiburo [36] in Florida, USA. Sphyra tiburo had distinct core use areas that moved throughout the study area with some areas eventually re-used over several months. This somewhat nomadic pattern of movement was attributed to foraging for swimmer crabs in seagrass beds [36]. Thus, C. ignobilis movement patterns may also be related to the presence and movement of preferred prey or could be the result of environmental parameters. For example, areas with strong current flow may offer productive foraging ground [20,37], and consequently, C. ignobilis may move their activity space around reefs to improve foraging opportunities.

Different environmental drivers were responsible for the presence and depth use of C. ignobilis in the central GBR region; however, little or no relationship was apparent relative to space use. Water temperature was a significant factor in C. ignobilis presence and depth use, which provided insight into their daily and seasonal movement patterns. Individuals were more present in the region in winter and also with low average daily water temperature. This study also showed evidence of seasonal effects on depth use with increases in mean depth occurring from autumn to spring. These results differed from other large coral reef fish such as L. miniatus ([32], Currey LM, Heupel MR, Simpfendorfer CA, Williams AJ: Do environmental variables influence movement patterns of an exploited coral reef fish?, forthcoming) or P. leopardus $[33,34]$ which appear to move deeper with increases in water temperature, suggesting that individuals were remaining in preferred temperature conditions. A change of a few degrees in water temperature can influence the physical condition, swimming speed and performance $[38,39]$, reproductive performance [40] and growth rate [41] of individuals; consequently, it is advantageous for individuals to remain in areas with optimal temperatures. However, C. ignobilis has a wide distribution ranging from the tropics to subtropics $[21,22]$ and high reef fidelity. The central GBR includes semi-isolated coral reef habitats ( 5 to $25 \mathrm{~km}$ apart) separated by deeper channels (approximately $70 \mathrm{~m}$ ), so there is variability between and within reefs; thus, C. ignobilis may have greater tolerance to environmental changes ([3], Espinoza $M$, Lédée EJI, Simpfendorfer CA, Tobin AJ, Heupel MR.: Contrasting movements and connectivity of reefassociated sharks using acoustic telemetry: implications for management, forthcoming). Consequently, it is unlikely that water temperature directly influenced 
C. ignobilis presence or depth use due to biological limitations.

One possible explanation for the difference in the presence and depth use observed is that $C$. ignobilis may be responding to another ecological factor such as the availability of prey species which do respond to temperature changes [4]. The presence of prey can depend on season, and some species are found at different depths in the water column which may provide drivers for movement. This type of movement would be consistent with those of other coral reef predator species such as C. amblyrhynchos in Hawaii [42]. The presence of C. ignobilis was higher at night, and individuals were also closer to the surface during night and low tide periods. C. ignobilis diet consists of mostly reef fish and invertebrates, including octopus and adult lobsters that use shallow-reef habitats [13,21]. Moreover, prey species use shallow areas as foraging grounds when decreases in light occur [43]. Therefore, C. ignobilis vertical movements may have been related to the distribution of prey species in the water column at night [4].

Other environmental factors were also significant for the presence and depth use of C. ignobilis. For example, wind had a significant effect on depth use, with individuals moving shallower when winds were high. This observation may have been the result of an environmental driver on predator or prey. Wind speed was also a significant factor in presence/absence, but wind is known to decrease the detection ability of acoustic receivers due to increased noise $[3,44]$. Performance of the acoustic receivers or other methods employed must be considered carefully when interpreting drivers of movement and the implications of the data.

This study provides a better understanding of $C$. ignobilis movement patterns and interactions with their environment to develop sound management plans. By identifying $C$. ignobilis movement capabilities and site fidelity within both activity spaces and aggregation sites, information for improved protection such as marine protected area (MPA) delineation $[7,11]$ is obtained. Caranx ignobilis had high reef fidelity, and consequently, a reef scale MPA might provide significant benefit for the species. However, $50 \%$ of individuals were rarely or not detected within the array. Undetected individuals may have been just outside the detection range of receivers, undertook long movements to the Australian coast, or moved to more distant parts of the Great Barrier Reef outside the study area. Consequently, more research is needed to determine if reef-scale management will benefit the species adequately or only protect a portion of the population. Finally, C. ignobilis inter-reef movements occurred during the summer new moons suggesting new moon closures would provide additional protection during spawning movements. Protection of individual reefs and spawning aggregations would be beneficial where management intervention is required for this species.

\section{Conclusions}

Within the central GBR region, C. ignobilis exhibited high reef fidelity to their tagging reef with limited movement to other reefs or regions. Intra-reef movements were somewhat nomadic and may have been related to the presence and movement of prey species. Water temperature, light intensity and time of day affected the presence and depth use of $C$. ignobilis within their tagging reef. The use of a variety of tracking methods will be necessary to fully understand $C$. ignobilis movement patterns at the reef scale by providing different spatial and temporal levels of information. Caranx ignobilis were adapted to environmental changes; however, they are susceptible to overfishing in other regions and would benefit from reef-scale MPAs and spawning closure management measures.

\section{Methods}

\section{Study site and acoustic monitoring}

This research was conducted from 2012 to 2014 in the central section of the Great Barrier Reef located off the north-east coast of Australia (Figure 7). The study region stretched from Bramble Reef ( $18^{\circ} 24^{\prime}$ S), located approximately $100 \mathrm{~km}$ north of Townsville to Pinnacle Reef $\left(19^{\circ} 01^{\prime} \mathrm{S}\right)$, located approximately $80 \mathrm{~km}$ east of Townsville. Depth within the region varies from 0 to $70 \mathrm{~m}$ (Figure 7). Seventeen reefs within the study region were monitored by 48 acoustic receivers (VR2W Vemco Ltd, Halifax, Nova Scotia, Canada) deployed in 2011 and a further 8 deployed in 2013 (Figure 7). For detailed information on the study area description and acoustic receiver deployment, see Espinoza et al. [20]. Receivers were downloaded twice per year and had a detection range estimated to vary between 150 and $300 \mathrm{~m}$ [20]. Sentinel acoustic transmitters were permanently deployed on sandy bottom at distances between 110 and $190 \mathrm{~m}$ from receivers located at Helix and John Brewer Reefs. Sentinels were anchored at approximately $40 \mathrm{~m}$, attached to a $25-\mathrm{m}$ mooring rope with heavy duty cable ties and suspended in the water column at approximately $15 \mathrm{~m}$ with a buoy. Sentinel tag data were used to establish long-term detection range of transmitters and identify any diel patterns in transmitter detectability. Sampling and tagging efforts were concentrated at John Brewer, Lodestone, Keeper, Helix, Glow and Wheeler Reefs. Reefs had similar characteristics (that is, structure, slope and habitat); however, they differed in size [20]. John Brewer was the largest reef with approximately $24.6 \mathrm{~km}^{2}$, then Glow, Lodestone and Keeper with approximately $8.8 \mathrm{~km}^{2}$, approximately $8.7 \mathrm{~km}^{2}$ and approximately $7.1 \mathrm{~km}^{2}$, respectively. Wheeler and Helix were the smallest reefs with 


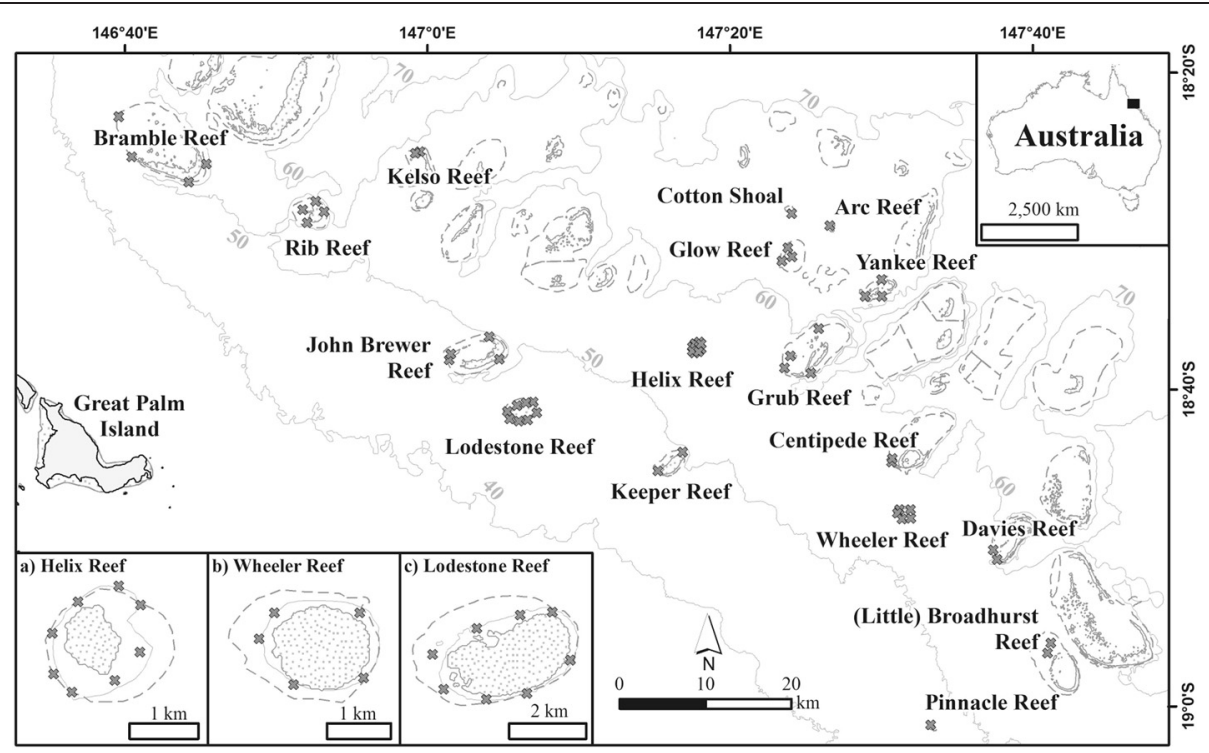

Figure 7 Map of the Townsville reefs in the central Great Barrier Reef. Grey " $x$ " symbols represent the locations of receivers within the Townsville reefs region, dotted grey lines indicate reef boundaries, dotted dark grey polygons represent the drying reef, light grey lines represent bathymetry within the region. Top right inset indicates location of the Townsville reefs along the Australian coast and bottom left insets indicate the location of the receivers on (a) Helix Reef, (b) Wheeler Reef and (c) Lodestone Reef. Light grey lines within the insets represent the 20-m contour line. Bathymetry data generated from Beaman [45].

approximately $2.9 \mathrm{~km}^{2}$ and approximately $1.6 \mathrm{~km}^{2}$, respectively.

Caranx ignobilis were captured by rod and reel using artificial lures. Barbs on hooks were flattened to reduce tissue damage during capture. After capture, individuals were placed in a large water-filled bin, containing Aqui-S ${ }^{\odot}$ diluted with seawater (1:10,000; AQUI-S New Zealand Ltd, Wellington, New Zealand), and surgically fitted with a $13 \mathrm{~mm} \times 45 \mathrm{~mm}$ acoustic transmitter (V13P-1H, Vemco Ltd, Halifax, Nova Scotia, Canada). Acoustic transmitters were implanted intra-muscularly in the anterior dorsal region where the muscle tissue was thickest to ensure longterm retention. The incision was closed with two running stitches using Maxon polyglyconate synthetic absorbable sutures with disposable needles. All surgical procedures were completed in less than $5 \mathrm{~min}$, and after surgery, individuals were measured to the nearest centimeter fork length and tagged with a dart tag (PDS; Hallprint $\odot$, Hallprint Pty Ltd, Hindmarsh valley, Australia) before release at the site of capture. Transmitters emitted a coded acoustic signal at $69 \mathrm{kHz}$ with a pseudo-randomised ping rate between 120 and $200 \mathrm{~s}$ to reduce collision of signals between tags; estimated battery life was 364 days. Transmitters were equipped with depth sensors with a maximum depth rating of $50 \mathrm{~m}$.

\section{Environmental data}

Environmental data were obtained from three different sources. Water temperature, wind speed, rainfall, light intensity and barometric pressure were sourced from an
Australian Institute of Marine Science (AIMS) weather station and Integrated Marine Observing System sensors on Davies Reef at the southern end of the acoustic array [46]. Average light intensity was measured as downwelling photosynthetically active (400 to $700 \mathrm{~nm}$ ) radiation in $\mu \mathrm{mol} / \mathrm{s} / \mathrm{m}^{2}$ using an underwater quantum sensor (LI-192SA, LI-COR Inc., Lincoln, NE, USA). Moon illumination (luminosity) was sourced from the United States Naval Observatory (http://aa.usno.navy.mil/data/docs/ MoonFraction.php) and tidal heights from the Bureau of Meteorology of Australia (http://www.bom.gov.au/). Environmental data were recorded at a variety of temporal scales, and mean values were aggregated by month (Additional file 4 showing monthly environmental values for Townsville reefs region in the central Great Barrier Reef) for analyses of space use, by day for analyses of presence/absence and by hour for analyses of depth use.

\section{Data analysis}

Detection data for each individual were exported from a VUE database (Vemco Division, Amirix Systems Inc., Halifax, Nova Scotia, Canada) and analysed in the R statistical environment [47]. A general investigation of reef and temporal patterns was undertaken using analysis of variance (ANOVA); first to compare fish size, mean number of days and maximum consecutive days present between tagging reefs. Then, to investigate a possible diel movement pattern of C. ignobilis, mean detections were calculated per hour over the period of the study and, separated into day (between 0600 to 1759 h) and night 
(between 1800 to $0559 \mathrm{~h}$ ) phases. Paired $t$-tests (assuming unequal-variance) were used to determine significance between phases. Detections were standardised based on sentinel tags, and Payne et al. [48] correction was used to confirm diel differences.

\section{Presence/absence}

A residency index was calculated for each individual by dividing the number of days an individual was detected within the study area by the days at liberty (that is, duration of transmitter life). Individuals were considered present in the study area if they were detected at least twice per day. Residency index ranged from 0 (not detected on any day) to 1 (detected on all days); difference in residency index between reefs was tested using ANOVA.

Generalized linear mixed-effects models (GLMM; R package 'Ime'; [49]) were used to examine the effect of fish size and environmental factors on presence/absence using the glmer function from the 'lme4' package [50]. For GLMM purposes, the days an individual was present were assigned a value of one and when absent a value of zero. The global model was fitted with a binomial error distribution using a logit link and a nAGQ value of seven [51]. The nAGQ was set to run an adaptive GaussHermite quadrature (AGQ) model to increase the model estimation accuracy [52].

\section{Space use}

Space use was estimated by vKUD following an approach used by Heupel and Simpfendorfer [3]. In this approach, each reef was considered as a linear system and the western tip of the reef edge as a starting point. Horizontal positions of individuals along the reef were estimated by calculating the distance from the starting point to the location of each detection and averaging this over a 2-h period using the centre of activity (COA) approach of Simpfendorfer et al. [53]. Depth was also averaged for each 2-h period and used in conjunction with COAs to provide two-dimensional position estimates [3]. Monthly 50\% (core use) and 95\% (extent) vKUD [3] were calculated based on position estimates for each individual ( $\mathrm{R}$ package 'ks'; [54]). Only individuals with >10 COAs per month were used in the analysis. Monthly vKUD overlaps were estimated for each individual to determine the re-use of space over time and between individuals at the same reef in months where they co-occurred. ANOVA was used to examine differences in monthly overlap between individuals and reefs.

GLMMs were used to examine the influence of fish size and environmental factors on the space use of $C$. ignobilis in the Townsville reefs region. Monthly core use and extent estimates were transformed to normality using a square root transformation. Tide height and moon illumination were not included in the GLMM analysis as they were not informative at a monthly scale.

\section{Depth use}

Caranx ignobilis depth use was investigated hourly. An ANOVA was used to test variation in individual depth use between reefs in the central GBR region. Effects of fish size and environmental factors on vertical distribution were examined using the lme function from the 'nlme' package [49]. Mean depth was square root transformed to normalise the data. Moon illumination data was not available at an hourly scale so was not included in the GLMM analysis.

\section{Environmental effects}

A series of models were applied to explore the effects of season, fish size and environmental data on the movement patterns of $C$. ignobilis. In each case, fixed factors were centred to simplify interpretation and facilitate comparison of their importance [55]. Individual was included as a random factor to enable population-level prediction and account for the repeated-measures nature of the data [51]. Collinearity between biological (that is, fish size) and environmental factors was assessed using Pearson correlation coefficients and variance inflation factors (VIF; $R$ package 'car'; [56]). If a factor had an absolute Pearson correlation coefficient $>0.8$ and a VIF value $>3$, it indicated collinearity with other factors and the factor was dropped from the analysis. Barometric pressure was not included in the presence/absence and space use global models based on Pearson correlation coefficients and VIF values due to collinearity with water temperature. In addition, rainfall was not included in the depth use global model due to violation of collinearity based on Pearson's residuals.

Differences in presence/absence, space use and depth use between summer (December to February), autumn (March to May), winter (June to August) and spring (September to November) were examined independently of other environmental factors to remove correlation effects and reduce complexity of mixed-effects models. Wald $Z$ tests were used to determine the overall seasonal effect compared to the null model.

The effects of fish size and environmental factors on presence/absence, space use and depth use were investigated using mixed-effects models. For each metric, global models were fitted with different weight functions to account for heterogeneity of variance. The corrected $\mathrm{AIC}_{c}$ was calculated for each model. The models with the lowest $\mathrm{AIC}_{c}$ values, indicating greater support for the model, were selected [57]. Diagnostics plots (that is, residuals plot and auto-correlation function plot) and tests (over-dispersion) evaluated goodness of fit [58,59]. If autocorrelation was present, global models were fitted with 
different correlation functions to account for temporal autocorrelation and heteroscedasticity. The corrected Akaike's information criterion was re-calculated, and final models with the lowest $\mathrm{AIC}_{c}$ values were selected for the analyses.

The best model (lowest $\mathrm{AIC}_{c}$ ) for core use (50\% vKUD) and extent (95\% vKUD) did not include weight functions. Auto-correlation was found for core use and extent, so the global models were fitted with different correlation functions; the best fitted models (lowest $\mathrm{AIC}_{c}$ ) included no correlation structure for core use and a correlation structure of order 1 (corAR1) for extent. Then, for the mean depth global model, homogeneity of variance was accounted for using a constant variance structure (varIdent) as weight function and auto-correlation using the correlation structure of order 1 (corAR1).

Multi-model inference was used to improve estimation of the effects of fish size and environmental factors on C. ignobilis space use, presence/absence and depth use. First, a set of nested models with different combinations of the fixed variables were derived from the global models $[51,60]$ using the dredge function from the 'MuMIn' package [61]. Using an information theoretic approach, nested model was ranked using $\mathrm{AIC}_{c}$. Second, model averaging based on Akaike weight was applied to well-fitting nested models $\left(\Delta \mathrm{AIC}_{c}<2\right)$. Best nested models were compared against the null model: $y \sim 1+(1 \mid$ ID $)$, where $y$ is the response, and significant differences were evaluated with maximum likelihood ratio tests $\left(\chi^{2}, P<0.05\right)$. Fixed variable estimates were calculated using the model.avg function from the 'MuMIn' package [61] to determine their relative importance and account for model selection uncertainty $[60,62]$. Finally, the full model-averaged coefficients (that is, shrinkage estimates) were used to account for nested model selection bias [58].

\section{Additional files}

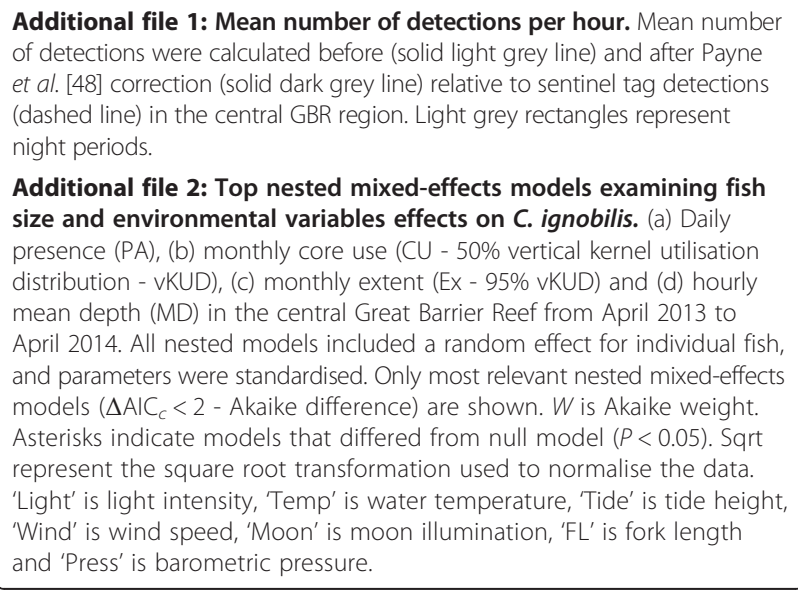

Additional file 2: Top nested mixed-effects models examining fish size and environmental variables effects on C. ignobilis. (a) Daily presence (PA), (b) monthly core use (CU - 50\% vertical kernel utilisation distribution - VKUD), (c) monthly extent (Ex - 95\% VKUD) and (d) hourly mean depth (MD) in the central Great Barrier Reef from April 2013 to April 2014. All nested models included a random effect for individual fish, and parameters were standardised. Only most relevant nested mixed-effects models ( $\triangle \mathrm{AIC}<2$ - Akaike difference) are shown. $W$ is Akaike weight. Asterisks indicate models that differed from null model $(P<0.05)$. Sqrt represent the square root transformation used to normalise the data. 'Light' is light intensity, 'Temp' is water temperature, 'Tide' is tide height, 'Wind' is wind speed, 'Moon' is moon illumination, 'FL' is fork length and 'Press' is barometric pressure.

Additional file 3: Fish size and environmental variable effects on $C$. ignobilis space use from model averaging analysis. (a) Core use (50\% vertical kernel utilisation distribution - vKUD) and (b) extent (95\% vKUD) in the central Great Barrier Reef from April 2013 to April 2014.

Additional file 4: Monthly environmental values for the Townsville reefs region in the central Great Barrier Reef. (a) mean wind speed, (b) mean barometric pressure, (c) mean water temperature, (d) mean rainfall and (e) mean light intensity. Source generated from the Australian Institute of Marine Science [46].

\section{Abbreviations}

AIMS: Australian Institute of Marine Science; ANOVA: analysis of variance; COA: centre of activity; GBR: Great Barrier Reef; GLMM: generalized linear mixed-effects models; MPA: marine protected area; VIF: variance inflation factors; VKUD: vertical kernel utilisation distribution.

\section{Competing interests}

The authors declare that they have no competing interests.

\section{Authors' contributions}

EJIL participated in the study conception, design, data collection, analysis and interpretation and drafted the manuscript. CAS participated in the study conception, design and data interpretation. MRH participated in the study conception, design, data collection and interpretation. AJT participated in the data collection and interpretation. All authors read, edited and approved the final manuscript.

\section{Acknowledgements}

We thank the staff and students at the Centre for Sustainable Tropical Fisheries and Aquaculture including J. Matley, M. Espinoza, F. de Faria, L. Currey, P. Yates and $\mathrm{V}$. Udyawer and also M. Kaminski for their support of this project. We would also like to thank the editors and two anonymous referees for their comments on the manuscript. Project funding was awarded to M.R. Heupel via the National Environmental Research Project. E.J.I. Lédée was supported by an Australian Postgraduate Award and James Cook University's College of Marine and Environmental Sciences. All surgical procedures were conducted under Animal Ethics permit A1933 approved by the James Cook University. Map data were provided by the Great Barrier Reef Marine Park Authority, Queensland Department of Environment and Resource Management and Robin Beaman.

\section{Author details}

${ }^{1}$ Centre for Sustainable Tropical Fisheries and Aquaculture, College of Marine and Environmental Sciences, Building 34, James Cook University, Townsville, Queensland 4811, Australia. ${ }^{2}$ AIMS@JCU, Australian Institute of Marine Science, College of Marine and Environmental Sciences, Building 17, James Cook University, Townsville, Queensland 4811, Australia. ${ }^{3}$ Australian Institute of Marine Science, PMB No 3, Townsville MC, Townsville, Queensland 4810, Australia.

Received: 23 December 2014 Accepted: 5 March 2015

Published online: 01 April 2015

\section{References}

1. De'ath G, Fabricius KE, Sweatman H, Puotinen M. The 27-year decline of coral cover on the Great Barrier Reef and its causes. Proc Natl Acad Sci U S A. 2012:109:17995-9.

2. Chin A, Kyne PM. Vulnerability of chondrichthyan fishes of the Great Barrier Reef to climate change. In: Johnson JE, Marshall PA, editors. Climate Change and the Great Barrier Reef: a vulnerability assessment. Townsville: Great Barrier Reef Marine Park Authority and Australian Greenhouse Office; 2007. p. 393-425.

3. Heupel MR, Simpfendorfer CA. Importance of environmental and biological drivers in the presence and space use of a reef-associated shark. Mar Ecol Prog Ser. 2014;496:47-57.

4. Richards BL, Williams ID, Vetter OJ, Williams GJ. Environmental factors affecting large-bodied coral reef fish assemblages in the Mariana Archipelago. PLoS One. 2012;7:e31374.

5. Croft D, James R, Krause J. Exploring animal social networks. Princeton, New Jersey: Princeton University Press; 2008. 
6. Espinoza M, Cappo M, Heupel MR, Tobin AJ, Simpfendorfer CA. Quantifying shark distribution patterns and species-habitat associations: implications of marine park zoning. PLoS One. 2014;9:e106885

7. Green AL, Maypa AP, Almany GR, Rhodes KL, Weeks R, Abesamis RA, et al. Larval dispersal and movement patterns of coral reef fishes, and implications for marine reserve network design. Biol Rev. 2014. doi:10.1111/brv.12155

8. Kadmon R, Benjamini Y. Effects of productivity and disturbance on species richness: a neutral model. Am Nat. 2006;167:939-46.

9. Heithaus MR, Frid A, Wirsing AJ, Worm B. Predicting ecological consequences of marine top predator declines. Trends Ecol Evol. 2008:23:202-10.

10. Nilsson GE, Crawley N, Lunde IG, Munday PL. Elevated temperature reduces the respiratory scope of coral reef fishes. Global Change Biol. 2009;15:1405-12

11. Dulvy NK, Freckleton RP, Polunin NVC. Coral reef cascades and the indirect effects of predator removal by exploitation. Ecol Lett. 2004;7:410-6.

12. Bascompte J, Melian CJ, Sala E. Interaction strength combinations and the overfishing of a marine food web. Proc Natl Acad Sci U S A. 2005;102:5443-7.

13. Dale JJ, Meyer CG, Clark CE. The ecology of coral reef top predators in the Papahānaumokuākea Marine National Monument. J Mar Biol. 2011;2011:1-14.

14. Myers RA, Baum JK, Shepherd TD, Powers SP, Peterson CH. Cascading effects of the loss of apex predatory sharks from a coastal ocean. Science. 2007:315:1846-50.

15. Dulvy NK, Fowler SL, Musick JA, Cavanagh RD, Kyne PM, Harrison LR, et al. Extinction risk and conservation of the world's sharks and rays. eLife. 2014;3:e00590

16. Sirot C, Villéger S, Mouillot D, Darnaude AM, Ramos-Miranda J, Flores-Hernandez D, et al. Combinations of biological attributes predict temporal dynamics of fish species in response to environmental changes. Ecol Ind. 2015;48:147-56.

17. Schlaff AM, Heupel MR, Simpfendorfer CA. Influence of environmental factors on shark and ray movement, behaviour and habitat use: a review. Rev Fish Biol Fisheries. 2014;24:1089-103.

18. FAO Fisheries and Aquaculture Department. The state of world fisheries and aquaculture. Rome: Food and Agriculture Organization of the United Nations; 2010.

19. Knip DM, Heupel MR, Simpfendorfer CA, Tobin AJ, Moloney J. Wet-season effects on the distribution of juvenile pigeye sharks, Carcharhinus amboinensis, in tropical nearshore waters. Mar Freshwater Res. 2011:62:658-67.

20. Espinoza M, Heupel MR, Tobin AJ, Simpfendorfer CA. Residency patterns and movements of grey reef sharks (Carcharhinus amblyrhynchos) in semi-continuous coral reef habitats. Mar Biol. 2015;162:343-58.

21. Sudekum AE, Parrish JD, Radtke RL, Ralston S. Life-history and ecology of large jacks in undisturbed, shallow, oceanic communities. Fish B-Noaa. 1991;89:493-513.

22. Wetherbee BM, Holland KN, Meyer CG, Lowe CG. Use of a marine reserve in Kaneohe Bay, Hawaii by the giant trevally, caranx ignobilis. Fish Res. 2004;67:253-63.

23. Webb PW. Body form, locomotion and foraging in aquatic vertebrates. Am Zool. 1984:24:107-20.

24. Sfakiotakis M, Lane DM, Davies JBC. Review of fish swimming modes for aquatic locomotion. IEEE J Oceanic Eng. 1999;24:237-52.

25. Nash KL, Welsh JQ, Graham NA, Bellwood DR. Home-range allometry in coral reef fishes: comparison to other vertebrates, methodological issues and management implications. Oecologia. 2015;177:73-83.

26. Lowe CG, Wetherbee BM, Meyer CG. Using acoustic telemetry monitoring techniques to quantify movement patterns and site fidelity of sharks and giant trevally around French frigate shoals and midway atoll. Atoll Res Bull. 2006;543:281-303.

27. Meyer CG, Holland KN, Papastamatiou YP. Seasonal and diel movements of giant trevally Caranx ignobilis at remote Hawaiian atolls: implications for the design of marine protected areas. Mar Ecol Prog Ser. 2007;333:13-25.

28. Fontes J, Schmiing M, Afonso P. Permanent aggregations of a pelagic predator at shallow seamounts. Mar Biol. 2014;161:1349-60.

29. Dagorn L, Holland KN, Itano DG. Behavior of yellowfin (Thunnus albacares) and bigeye (T-obesus) tuna in a network of fish aggregating devices (FADs). Mar Biol. 2007;151:595-606.

30. Brown H, Benfield MC, Keenan SF, Powers SP. Movement patterns and home ranges of a pelagic carangid fish, Caranx crysos, around a petroleum platform complex. Mar Ecol Prog Ser. 2010;403:205-18.

31. Afonso P, Fontes J, Holland KN, Santos RS. Multi-scale patterns of habitat use in a highly mobile reef fish, the white trevally Pseudocaranx dentex, and their implications for marine reserve design. Mar Ecol Prog Ser. 2009;381:273-86.
32. Williams AJ, Davies CR, Mapstone BD, Russ GR. Scales of spatial variation in demography of a large coral reef fish: an exception to the typical model? Fish B-Noaa. 2003;101:673-83.

33. Matley JK, Heupel MR, Simpfendorfer CA. Depth and space use of leopard coral grouper Plectropomus leopardus using passive acoustic tracking. Mar Ecol Prog Ser. 2015;521:201-16.

34. Bunt CM, Kingsford MJ. Movement, habitat utilization and behaviour of coral trout Plectropomus leopardus during and after the reproductive period on the southern Great Barrier Reef. Mar Ecol Prog Ser. 2014;496:33-45.

35. DeVantier LM, De'ath G, Turak E, Done TJ, Fabricius KE. Species richness and community structure of reef-building corals on the nearshore Great Barrier Reef. Coral Reefs. 2006;25:329-40.

36. Heupel MR, Simpfendorfer CA, Collins AB, Tyminski JP. Residency and movement patterns of bonnethead sharks, Sphyrna tiburo, in a large Florida estuary. Environ Biol Fish. 2006;76:47-67.

37. Wetherbee BM, Crow GL, Lowe CG. Distribution, reproduction and diet of the gray reef shark Carcharhinus amblyrhynchos in Hawaii. Mar Ecol Prog Ser. 1997;151:181-9.

38. Henderson MJ, Fabrizio MC, Lucy JA. Movement patterns of summer flounder near an artificial reef: effects of fish size and environmental cues. Fish Res. 2014:153:1-8.

39. Munday PL, Jones GP, Pratchett MS, Williams AJ. Climate change and the future for coral reef fishes. Fish Fish. 2008;9:261-85.

40. Donelson JM, Munday PL, McCormick MI, Pankhurst NW, Pankhurst PM. Effects of elevated water temperature and food availability on the reproductive performance of a coral reef fish. Mar Ecol Prog Ser. 2010;401:233-43.

41. Munday PL, Kingsford MJ, O'Callaghan M, Donelson JM. Elevated temperature restricts growth potential of the coral reef fish Acanthochromis polyacanthus. Coral Reefs. 2008;27:927-31.

42. Papastamatiou YP, Wetherbee BM, Lowe CG, Crow GL. Distribution and diet of four species of carcharhinid shark in the Hawaiian Islands: evidence for resource partitioning and competitive exclusion. Mar Ecol Prog Ser. 2006;320:239-51.

43. Luo J, Serafy JE, Sponaugle S, Teare PB, Kieckbusch D. Movement of gray snapper Lutjanus griseus among subtropical seagrass, mangrove, and coral reef habitats. Mar Ecol Prog Ser. 2009;380:255-69.

44. Udyawer V, Chin A, Knip DM, Simpfendorfer CA, Heupel MR. Variable response of coastal sharks to severe tropical storms: environmental cues and changes in space use. Mar Ecol Prog Ser. 2013;480:171-83.

45. Beaman RJ. Project 3DGBR: A high-resolution depth model for the Great Barrier Reef and Coral Sea. Cairns, Australia: MTSRF; 2010.

46. Australian Institute of Marine Science. Table generated using Davies Reef Weather Station. Retrieved 11th June 2014, from Long term Monitoring and Data Centre http://weather.aims.gov.au/

47. R Development Core Team. R: A Language and Environment for Statistical Computing. Vienna, Austria; 2014. Version 3.1.0. http://www.R-project.org

48. Payne NL, Gillanders BM, Webber DM, Semmens JM. Interpreting diel activity patterns from acoustic telemetry: the need for controls. Mar Ecol Prog Ser. 2010;419:295-301.

49. Pinheiro J, Bates D, DebRoy S, Sarkar D, R Core Team. nlme: Linear and Nonlinear Mixed Effects Models. 2014. R package version 3.1-117. http://CRAN.R-project.org/package=nlme

50. Bates D, Maechler M, Bolker BM, Walker S. Ime4: Linear mixed-effects models using Eigen and S4. 2014. R package version 1.1-6. http://CRAN.R-project. org/package=Ime4

51. Bolker BM, Brooks ME, Clark CJ, Geange SW, Poulsen JR, Stevens MH, et al. Generalized linear mixed models: a practical guide for ecology and evolution. Trends Ecol Evol. 2009;24:127-35.

52. Pinheiro JC, Chao EC. Efficient Laplacian and adaptive Gaussian quadrature algorithms for multilevel generalized linear mixed models. J Comput Graph Stat. 2006;15:58-81.

53. Simpfendorfer CA, Heupel MR, Hueter RE. Estimation of short-term centers of activity from an array of omnidirectional hydrophones and its use in studying animal movements. Can J Fish Aquat Sci. 2002;59:23-32.

54. Duong T. ks: kernel smoothing. 2014. R package version 1.9.2. http://CRAN. R-project.org/package=ks

55. Schielzeth $\mathrm{H}$. Simple means to improve the interpretability of regression coefficients. Methods Ecol Evol. 2010;1:103-13.

56. Fox J, Weisberg S. An $\{R\}$ companion to applied regression. Thousand Oaks CA: Sage; 2011. http://socserv.socsci.mcmaster.ca/jfox/Books/Companion.

57. Burnham KP, Anderson DR. Multimodel inference - understanding AIC and BIC in model selection. Sociol Method Res. 2004;33:261-304. 
58. Burnham KP, Anderson DR. Information and likelihood theory: a basis for model selection and inference. In: Burnham K, Anderson D, editors. Model selection and multimodel inference. New York, USA: Springer; 2002. p. 49-97.

59. Zuur AF, leno EN, Elphick CS. A protocol for data exploration to avoid common statistical problems. Methods Ecol Evol. 2010;1:3-14.

60. Johnson JB, Omland KS. Model selection in ecology and evolution. Trends Ecol Evol. 2004;19:101-8.

61. Barton K. MuMIn: Multi-model inference. 2014. R package version 1.10.0. http://CRAN.R-project.org/package=MuMln

62. Grueber CE, Nakagawa S, Laws RJ, Jamieson IG. Multimodel inference in ecology and evolution: challenges and solutions. J Evol Biol. 2011;24:699-711.

\section{Submit your next manuscript to BioMed Central} and take full advantage of:

- Convenient online submission

- Thorough peer review

- No space constraints or color figure charges

- Immediate publication on acceptance

- Inclusion in PubMed, CAS, Scopus and Google Scholar

- Research which is freely available for redistribution 